\title{
Psychological States and Lymphocyte $\beta$-Adrenergic Receptor Responsiveness
}

\author{
Bum-Hee Yu, M.D., Joel E. Dimsdale, M.D., and Paul J. Mills, Ph.D.
}

There is a complex interplay between psychological states and biochemical factors. $\beta$-Adrenergic receptor responsiveness is altered in some patients with depression and anxiety disorders, but the relation between various psychological states and receptor function in a normal population is unknown. We measured lymphocyte $\beta$-adrenergic receptor density $\left(B_{\max }\right)$, sensitivity (cAMP ratio), the Profile of Mood States (POMS), and Spielberger State-Trait Anxiety Inventory (STAI) in 39 hypertensives and 81 normotensives. We examined correlations between log normalized receptor variables and psychological states. Log $B_{\max }$ showed negative correlations with age and with POMS tension-anxiety, depression-dejection, and anger-hostility.
Log cAMP ratio did not show significant correlations with POMS and STAI ratings. In step-wise multiple regression analyses, $36 \%$ of the variance in $B_{\max }$ was accounted for by POMS tension-anxiety, and age. Our study suggests that increased POMS tension-anxiety was highly associated with down-regulation of $\beta$-adrenergic receptors, even in subjects who do not have psychiatric illness. Numerous psychological states could be associated with changes of $\beta$-adrenergic receptor responsiveness in a normal population. [Neuropsychopharmacology 21:147-152, 1999] ( 1999 American College of Neuropsychopharmacology. Published by Elsevier Science Inc.
KEY WORDS: $\beta$-Adrenergic receptor; Anxiety; Depression; Anger; Psychological state

There is a strong interplay between psychological states and physiology. This interplay has traditionally been studied extensively in terms of hormonal levels. More recently, investigators have begun to explain how such factors relate to receptor physiology. $\beta$-Adrenergic receptor responsiveness may be altered in patients with such psychiatric diseases as depression (Pandey et al. 1987; Magliozzi et al. 1989) and panic disorder (Nesse et al. 1984; Brown et al. 1988; Aronson et al. 1989). In panic disorder, reduced $\beta$-adrenergic receptor responsiveness has been noted in two ways, with both reduced recep-

From the Department of Psychiatry (B-HY), Samsung Medical Center, Sung-Kyun-Kwan University, College of Medicine, Seoul, South Korea; and Department of Psychiatry and Cancer Center (JED, PJM), University of California, San Diego, California.

Address correspondence to: J.E. Dimsdale, M.D., UCSD, 9500 Gilman Drive, La Jolla, CA 92093-0804.

Received August 10, 1998; revised November 9, 1998; accepted November 20, 1998. tor density and reduced responsivity to isoproterenol (Maddock et al. 1993).

Adrenergic receptor regulation is closely related to psychological stressors (Graafsma et al. 1989). $\beta$-Adrenergic receptor function is closely affected by numerous psychological stressors; for example, individuals with high life stress have lower $\beta$-adrenergic receptor sensitivity (Dimsdale et al. 1994). Recently, hostility has been shown to be associated with $\beta$-adrenergic receptor down-regulation in healthy young males (Suarez et al. 1997). All of these studies suggest that adrenergic receptors may be regarded as an important link between humoral signals influenced by psychological stressors and end organ responsiveness. However, normative information still needs to be acquired concerning the relationship between various psychological states and $\beta$-adrenergic receptor responsiveness in a nonpsychiatric population.

Human leukocytes offer a useful model for studying the role of $\beta$-adrenergic receptor responsiveness in patients with medical or psychiatric illness (Pandey et al. 
1987) and in healthy subjects (Mills and Dimsdale 1993). The use of lymphocyte $\beta$-adrenergic receptors as a model for central $\beta$-receptors is not as well established as the use of lymphocyte $\beta$-receptors for such peripheral tissues as the heart and lung. Nonetheless, Mann et al. (1990) reported a normalization of blunted lymphocyte $\beta$-receptors in depression following treatment. In addition, Brodde et al. (1986) reported that alterations in lymphocyte $\beta$-adrenoceptors mirror changes in $\beta$-adrenoceptors in other tissues less accessible in human studies. There are two major techniques for measuring $\beta$-adrenergic receptor responsiveness in human leukocytes; measuring receptor density $\left(B_{\max }\right)$ and sensitivity. $\beta$-Adrenergic receptor density in lymphocytes is defined as the number of receptors/cell for intact cells, and as pico- or femto-moles $/ \mathrm{mg}$ protein for membranes. $\beta$-Adrenergic receptor sensitivity is defined as the efficiency with which agonist binding translates into stimulation of adenylate cyclase and subsequent production of the second messenger cyclic AMP (Mills and Dimsdale 1988).

We hypothesized that the relationship between altered adrenergic receptor responsiveness and mood could extend to a broader population that does not have psychiatric illness. This study examines whether $\beta$-adrenergic responsiveness is related to self-rated measures of mood states in a group of psychiatrically nonsymptomatic normotensives and unmedicated hypertensive subjects.

\section{METHODS AND MATERIALS}

All subjects were studied after obtaining written consent and were recruited from the San Diego community through advertisement or word-of-mouth referral. We recruited 120 men and women between the ages of 20 59 years who were composed of 39 hypertensives and 81 normotensives. Subjects were excluded if they had a history of other major medical or psychiatric problems or hypertension greater than 180/110 $\mathrm{mmHg}$. We also excluded women taking birth control pills. For the 39 hypertensives, only four were receiving antihypertensive medications (two on a $\beta$-blocker, one on a diuretic, and one on a calcium channel blocker), and these patients were tapered off their medications for more than 3 weeks before participation. Individuals whose resting seated blood pressure was greater than $140 / 90 \mathrm{mmHg}$ upon three repeated measurements on two occasions were categorized as hypertensive patients.

All subjects were hospitalized on a clinical research unit. On the first night of hospitalization, each patient had a heparin lock placed in a forearm vein. The next morning, before the subject was ambulatory, a blood sample was taken to assess lymphocyte $\beta$-adrenergic receptor function. Lymphocyte isolation and receptor assays to determine $\beta_{2}$-adrenergic receptors were conducted according to previously published methods (Mills et al. 1993). Lymphocytes were isolated from whole blood according to the method of Boyum (1968), and contaminating leukocytes and platelets were removed by centrifugation. $\beta$-Adrenergic receptors can be in either a high-affinity, coupled (functionally capable of coupling to the G-protein-adenyl cyclase complex following agonist binding) or a low- affinity, uncoupled state. We used isoproterenol stimulation of cAMP to assess the functional state of the receptors and receptor binding to determine receptor density. Binding data include both the coupled and uncoupled receptors; whereas, the isoproterenol stimulation data yield an index of primarily high-affinity, coupled receptors. Lymphocyte $\beta_{2}$-adrenergic receptor sensitivity was determined in whole cells by quantifying cAMP accumulation following incubation with $10 \mu \mathrm{M}$ isoproterenol. Basal, nonstimulated, intracellular cAMP was also determined. $\beta$-adrenergic receptor sensitivity was defined as the ratio of stimulated to basal cAMP (the cAMP ratio), because the ratio helps reduce interassay variability of the $\beta$-adrenergic receptor sensitivity index and helps control for possible variations in $\beta$-adrenergic receptors in $\mathrm{T}$ and $\mathrm{B}$ cell populations across individuals (Feldman et al. 1987). Lymphocyte $\beta_{2}$-adrenergic receptor density $\left(B_{\max }\right)$ was determined using radioligand binding with [ $\left.{ }^{125} \mathrm{I}\right]$-iodopindolol at six concentrations from 10 to 320 pM for 1 hour at $37^{\circ} \mathrm{C}$. Specific binding was determined by using $10^{-6} \mathrm{M} 1$-propranolol.

Subjects completed the Profile of Mood States (POMS, McNair et al. 1971), and the Spielberger StateTrait Anxiety Inventory (STAI, Spielberger et al. 1983) 1 hour after obtaining blood sample. POMS, a self-administered, adjective rating scale composed of 65 items, measures six clearly defined dimensions of mood such as tension-anxiety (possible raw score range, 0-36), depression-dejection (0-59), anger-hostility (0-44), vigoractivity (0-31), fatigue-inertia (0-28), and confusion-bewilderment (0-28) during the past 1 week, including the test day.

All receptor values were normalized using natural logarithms, because the varying receptor measures were not normally distributed. Data were analyzed by $t$-test, univariate correlation, and multiple regression analyses. Analyses were run on SPSS 7.0 version software.

\section{RESULTS}

Table 1 shows summary data on subject characteristics. There was no statistically significant difference in age, race, and sex between normotensive and hypertensive subjects. Table 2 shows means and standard deviations for POMS and STAI ratings in all subjects. Table 3 
Table 1. The Sample Characteristics

\begin{tabular}{lccc}
\hline & Normotensive Group & Hypertensive Group & Total \\
\hline $\begin{array}{l}\text { Number } \\
\text { Age (years) } \\
\text { (mean } \pm \text { SD) }\end{array}$ & 81 & 39 & 120 \\
Sex & $37.8 \pm 7.8$ & $40.2 \pm 7.1$ & $38.5 \pm 7.7$ \\
$\quad$ Male & & & \\
Female & 56 & 31 & 87 \\
Race & 25 & 8 & 33 \\
$\quad$ White & 40 & 21 & 61 \\
$\quad$ Black & 38 & 18 & 56 \\
Hispanic & 3 & 0 & 3 \\
\hline
\end{tabular}

SD: standard deviation.

shows $B_{\max }$ and the cAMP ratio in normotensive and hypertensive groups; there was no difference in these receptor measures between the two groups. Between men and women, values of $B_{\max }(35.0 \pm 34.0$ vs. $21.6 \pm$ $31.9)$ and the cAMP ratio $(4.70 \pm 2.17$ vs. $4.45 \pm 1.64)$ were also not different. We did not find any difference in values of $B_{\max }(34.2 \pm 37.0$ vs. $31.1 \pm 32.6)$ and the cAMP ratio $(4.65 \pm 1.97$ vs. $4.76 \pm 2.09)$ between black and white subjects.

We examined correlation coefficients among log transformed receptor measures, age, and psychological state variables as measured by POMS and STAI scales. Natural $\log$ transformation of receptor measures resulted in normally distributed data. Given the number of correlations, we adjusted alpha level for multiple comparisons in our study by using Bonferroni correction and adjusted the significance level to $p \leqslant .005$.

$\mathrm{B}_{\max }$ was negatively correlated with age $(\mathrm{r}=-.375$, $p=.004)$. $\mathrm{B}_{\max }$ was also negatively correlated with POMS tension-anxiety $(\mathrm{r}=-.490, p<.001)$, depression-dejection $(\mathrm{r}=-.455, p<.001)$, and anger-hostility $(\mathrm{r}=-.439, p=.001)$ ratings but did not show significant correlations with STAI ratings. The cAMP ratio did not show significant correlations with either POMS or STAI ratings.

Table 2. Profile of Mood States (POMS) and Spielberger State-Trait Anxiety Inventory (STAI) Ratings (mean \pm standard deviation)



We then conducted step-wise multiple regression analyses to determine the relative importance of age and the POMS ratings in predicting the values of $B_{\max }$ (see Table 4). Regarding the values of $\mathrm{B}_{\max }$, POMS tension-anxiety accounted for $26 \%$ of the variance in $\log$ $\mathrm{B}_{\max }(\mathrm{r}=.511, p<.001)$ in the first step. In step 2, age entered the equation, and $36 \%$ of variance in $\log B_{\max }$ was accounted for by POMS tension-anxiety and age $(\mathrm{r}=.600, p<.001)$. Other variables did not add significant information.

\section{DISCUSSION}

We examined the association between the POMS ratings, the STAI ratings, and $\beta$-adrenergic receptor measures in a group composed of hypertensive and normotensive subjects, not complaining of any psychiatric illness. Although we cannot rule out "white coat hypertension," our patients classified as "hypertensive" were so labeled only after repeated blood pressure measurement. Michel et al. (1990) reported that the difference in $\beta$-adrenergic receptor measures between hypertensives and normotensives is not consistent in many studies. We wanted to include as many subjects in our study as possible and compared $\beta$-adrenergic receptor variables of hypertensive subjects with those of normotensive subjects. We found that there was no difference in receptor variables between the two groups. In addition, regarding the correlations between psychological rating scales and receptor measures, our findings were substantially the same, whether or not the hypertensive subjects were included.

There was a strong negative correlation between age and $\mathrm{B}_{\max }$. Step-wise multiple regression analysis indicated that age alone accounted for about $10 \%$ of the variance in $\mathrm{B}_{\max }$. Age-related adrenergic changes in central nervous system are still debatable with respect to $\beta$-adrenergic receptor binding. Kalaria (1989) reported a weak negative correlation with age for $\beta$-receptor bind- 
Table 3. $\mathrm{B}_{\max }$ and the ratio of isoproterenol-stimulated cAMP to basal cAMP (cAMP ratio) in normotensive and hypertensive groups (mean \pm standard deviation)

\begin{tabular}{lccc}
\hline & $\begin{array}{c}\text { Normotensive Group } \\
(\boldsymbol{n}=\mathbf{8 1})\end{array}$ & $\begin{array}{c}\text { Hypertensive Group } \\
(\boldsymbol{n}=\mathbf{3 9 )}\end{array}$ & $\begin{array}{c}\text { Total } \\
(\boldsymbol{n}=\mathbf{1 2 0})\end{array}$ \\
\hline $\mathrm{B}_{\max }(\mathrm{fmol} / \mathrm{mg}$ protein $)$ & $32.3 \pm 34.7$ & $32.8 \pm 33.3$ & $32.4 \pm 34.1$ \\
cAMP ratio & $4.6 \pm 2.2$ & $4.6 \pm 1.9$ & $4.6 \pm 2.1$ \\
\hline
\end{tabular}

ing in human prefrontal cortex. De Blasi et al. (1982) also reported age-related decreases in $\beta$-receptor binding in rat brain, but Harik et al. (1991) did not demonstrate such a finding in rat brain. Our findings support that age increase could be associated with decreased $\beta$-adrenergic receptor density in a normal population.

We found that POMS tension-anxiety, depressiondejection, and anger-hostility were negatively correlated with $\beta$-adrenergic receptor density. However, in step-wise multiple regression analysis, POMS tensionanxiety alone entered the equation and accounted for $26 \%$ of the variance in $B_{\max }$. It is known that the physiology of peripheral lymphocyte $\beta$-adrenergic receptors may be altered in patients with anxiety disorders, especially for panic disorder. Nesse et al. (1984) suggested that $\beta$-adrenergic receptors are down-regulated in patients with panic disorder. Most studies regarding $\beta$-adrenergic receptor binding and adrenergically mediated lymphocyte cAMP production also show a reduction in panic disorder (Maddock et al. 1993; Abelson and Cameron 1994). Both clinically significant agitation and panic anxiety can be associated with a reduction in lymphocyte $\beta$-adrenergic receptor binding (Magliozzi et al. 1989). Our results that tension-anxiety ratings are negatively correlated with $\beta$-adrenergic receptor density could extend these previous reports regarding the relationship between anxiety and $B_{\max }$ to a nonpsychiatric population.

Regarding no correlations between POMS tensionanxiety and cAMP ratio, the over-all correlations were stronger for $\mathrm{B}_{\max }$ than for the cAMP ratio in our study. $\beta$-Adrenergic receptor density is suggested to be a bit more stable measure than receptor sensitivity, which fluctuates more readily. Desensitization to catecholamines is often accompanied by a decrease in the affinity of the receptors for the hormone (uncoupling), followed by a decrease in the number of receptors (Motulsky and Insel 1982). Thus, the stronger correlations for $B_{\max }$ than for the cAMP may reflect the reduced variation of this measure. The same reasoning could explain why $B_{\max }$ correlates with age, but cAMP does not.

Many investigators have demonstrated a significant reduction in $\beta$-adrenergic receptor density in depressed patients as compared to healthy controls (Carstens et al. 1987; Pandey et al. 1987). Impaired cAMP production has been reported in agitated depressives, not in retarded depressives (Mann et al. 1985). Halper et al. (1988) also reported that both basal cAMP and isoproterenol-stimulated cAMP levels are lower in hospitalized, depressed patients. Most studies measuring $\beta$-adrenergic receptor stimulated adenyl-cyclase activity in mononuclear cells report decreased responsiveness in depressed patients as compared with healthy subjects, and this consistent decrease in leukocyte $\beta$-adrenergic receptor function may reflect an abnormality of $\beta$-receptor $/ \mathrm{G}$ protein/adenylcyclase complex (Manji et al. 1994). However, in our study, POMS depression-dejection rating did not predict the variance of $\beta$-adrenergic receptor density, and we did not observe a significant correlation between POMS depression-dejection rating and receptor sensitivity. Perhaps the link between depression and receptor changes can be observed only in patients with severe levels of depressive psychopathology.

Suarez et al. (1997) reported that healthy young males with high levels of hostility show decreased $\beta$-adrenergic receptor number and down-regulated $\beta$-adrenergic receptors, although there was no difference in isoproterenolstimulated cAMP levels between high- and low- hostility groups. However, we found that the POMS anger-hostility rating was not related to $B_{\max }$, although it was negatively correlated with $\beta$-adrenergic receptor density. This inconsistency may result from the difference in

Table 4. Results of Step-Wise Multiple Regression Analyses Regarding Log Normalized $B_{\max }$

\begin{tabular}{llccccc}
\hline Steps & Variables in the Equation & $\mathbf{R}$ & R Square & Beta & T & $p$-Value \\
\hline Step 1 & POMS tension-anxiety & .511 & .261 & -.456 & -4.353 & $p<.001$ \\
Step 2 & Age & .600 & .360 & -.319 & -3.044 & $p=.003$ \\
& Constant & & & & 9.156 & \\
\hline
\end{tabular}


study subjects between the two studies. Future study will be needed to clarify the relationship between anger-hostility and $\beta$-adrenergic receptor responsiveness considering age and gender factors in study subjects.

We did not find any difference in receptor measures between men and women. Previous reports in this area have not been consistent in terms of gender difference. Wheeldon et al. (1994) reported that females showed higher lymphocyte $\beta_{2}$-adrenoceptor density $\left(B_{\max }\right)$ and stimulated cAMP levels only during luteal phase than male subjects. Halper et al. (1984) reported that betareceptor binding indices $\left(\mathrm{B}_{\max }\right)$ in general did not differ between males and females; whereas, in older subjects, females showed higher cAMP ratio levels than males. However, because the means of $\beta$-receptor density were quite different between men and women, we cannot rule out that the lack of statistical difference in $\beta$-receptor density might result from a type II error. Besides no gender difference in receptor measures, we did not find any difference in receptor measures between black and white subjects. Although racial differences in lymphocyte $\beta$-receptor sensitivity to antihypertensive medication have been well recognized, Stein et al. (1990) reported that lymphocyte $\beta$-receptor density and cAMP ratio do not differ between blacks and whites.

Although we found a high negative correlation between POMS tension-anxiety rating and $\beta$-adrenergic receptor density, we did not get similar results between receptor measures and Spielberger anxiety scales. The Spielberger State and Trait Anxiety Inventory is a brief self-report measure that differentiates between state and trait anxiety. Spielberger trait anxiety measures more chronic anxiety; whereas, the POMs reflects very "here and now" mood states. We do not suggest that POMS tension-anxiety constitutes chronic anxiety disorders. Instead, we suggest that current mood states measured by the POMS are related to $\beta$-adrenergic receptor responsiveness in a normal population. Thus, the relationship between altered adrenergic receptor responsiveness and pathological mood states in anxiety disorders may extend to a general population who do not have psychiatric illness.

Our study has some important limitations in study design. We did not perform formal psychiatric diagnostic interviews. Our subjects were not receiving psychiatric counseling or psychotropic medications at the time of starting this study. However, the possibility that some of our subjects had undiagnosed psychiatric illness, such as depression or anxiety disorder, cannot be excluded completely. Another limitation of our study is that our sample might not be representative of the community, because they were recruited by advertisement. In addition, our sample was relatively small to extend and generalize our results to the general population. Nevertheless, our sample size is much larger than previous studies regarding mood states and $\beta$-adrenergic receptor responsiveness. Finally, we utilized cAMP accumulation following isoproterenol stimulation as an index of $\beta$-adrenergic receptor sensitivity. This technique, which relies on a maximal $10 \mu \mathrm{M}$ dose of isoproterenol to activate the $\beta$-receptor, yields a comparable assessment of the $\beta$-receptor as that obtained from agonist competition binding curves. This latter technique, however, differentiates the percentage of receptors in the coupled, high-affinity states $\left(R_{h}\right)$ and the uncoupled, low-affinity $\left(R_{L}\right)$ state. It could be that our findings would have been somewhat strengthened had we used agonist competition binding curves rather than a single, maximal dose technique.

In conclusion, increased POMS tension-anxiety was highly associated with down-regulation of $\beta$-adrenergic receptors, even in subjects who do not have psychiatric illness. Therefore, our study suggests that numerous psychological states could be associated with changes of $\beta$-adrenergic receptor responsiveness in a normal population.

\section{ACKNOWLEDGMENTS}

This research was supported by NIH grants HL-44915, Hl36005, and RR-00827 and by a grant from Samsung Medical Center, Sung-Kyun-Kwan University, College of Medicine.

\section{REFERENCES}

Abelson JL, Cameron OG (1994): Adrenergic dysfunction in anxiety disorders. In Cameron OG (ed), Adrenergic Dysfunction and Psychobiology. Washington, DC, American Psychiatric Press, pp 365-401

Aronson TA, Carasiti I, McBane D, Whitaker-Azmitia P (1989): Biological correlates of lactate sensitivity in panic disorder. Biol Psychiat 26:463-477

Boyum A (1968): Isolation of mononuclear cells and granulocytes from blood. Scand J Clin Invest 21:77-89

Brodde OE, Kretsch R, Ikezono K, Zerkowski HR, Reidemeister JC (1986): Human $\beta$-adrenoceptors: Relation of myocardial and lymphocyte $\beta$-adrenoceptor density. Science 231:1584-1585

Brown SL, Charney DS, Woods SW, Heninger GR, Tallman J (1988): Lymphocyte beta-adrenergic receptor binding in panic disorder. Psychopharmacology 94:24-28

Carstens ME, Engelbrecht AH, Russell VA, Aalbers C, Gagiano CA, Chalton DO, Taljaard JJ (1987): Beta-adrenoceptors on lymphocytes of patients with major depressive disorder. Psychiat Res 20:239-248

De Blasi A, Cotecchia S, Mennini T (1982): Selective changes of receptor binding in brain regions of aged rats. Life Sci 31:335-340

Dimsdale JE, Mills P, Patterson T, Ziegler M, Dillon E (1994): 
Effects of chronic stress on beta-adrenergic receptors in the homeless. Psychosom Med 56: 290-295

Feldman RD, Lawton WJ, McArdle WL (1987): Low-sodium diet corrects the defect in lymphocyte $\beta$-adrenergic responsiveness in hypertensive subjects. J Clin Invest 79:290-294

Graafsma SJ, van Tits LJ, van Heijst P, Reyenga J, Lenders JW, Rodrigues de Miranda JF, Thien T (1989): Adrenoceptors on blood cells in patients with essential hypertension before and after mental stress. J Hypertens 7:519-524

Halper JP, Mann JJ, Weksler ME, Bilezikian JP, Sweeney JA, Brown RP, Golbourne T (1984): Beta-adrenergic receptors and cyclic AMP levels in intact human lymphocytes : Effects of age and gender. Life Sci 35:855-863

Halper JP, Brown RP, Sweeney JA, Koesis JH, Peters A, Mann JJ (1988): Blunted $\beta$-adrenergic responsivity of peripheral blood mononuclear cells in endogenous depression isoproterenol dose-response studies. Arch Gen Psychiat 45:241-244

Harik SI, Sromek SM, Kalaria RN (1991): Alpha- and betaadrenergic receptors of the rat cerebral cortex and cerebral microvessels in aging and their response to denervation. Neurobiol Aging 12:567-573

Kalaria RN (1989): Characterization of $\left[{ }^{125} \mathrm{I}\right]$ HEAT binding to alpha1-receptors in human brain: Assessment in aging and Alzheimer's disease. Brain Res 501:287-294

Maddock RJ, Carter CS, Magliozzi JR, Gietzen DW (1993): Evidence that decreased function of lymphocyte betaadrenoceptors reflects regulatory and adaptive processes in panic disorder with agoraphobia. Am J Psychiat 150:1219-1225

Magliozzi JR, Gietzen D, Maddock RJ, Haack, Doran D, Goodman T, Weiler PG (1989): Lymphocyte beta-adrenoceptor density in patients with unipolar depression and normal controls. Biol Psychiat 26:15-25

Manji HK, Rudorfer MV, Potter WZ (1994): Affective disorders and adrenergic function. In Cameron OG (ed), Adrenergic Dysfunction and Psychobiology. Washington, DC, American Psychiatric Press, pp 365-401

Mann JJ, Brown RP, Halper JP, Sweeney JA, Koesis JH, Stokes PE, Bilezikian JP (1985): Reduced sensitivity of lymphocyte beta-adrenergic receptors in patients with endogenous depression and psychomotor agitation. New Engl J Med 313:715-720

Mann JJ, Mahler JC, Wilner PJ, Halper JP, Brown RP,
Johnson KS, Kocsis JH, Chen JS (1990): Normalization of blunted lymphocyte beta-adrenergic responsivity in melancholic inpatients by a course of electroconvulsive therapy. Arch Gen Psychiat 47:461-464

McNair DM, Lorr M, Droppleman LF (1971): EDITS manual for the profile of mood states. San Diego, CA, Educational and Industrial Testing Service

Michel MC, Brodde OE, Insel PA (1990): Peripheral adrenergic receptors in hypertension. Hypertension 16:107-120

Mills PJ, Dimsdale JE (1988): The promise of receptor studies in psychophysiologic research. Psychosom Med 50:555566

Mills PJ, Dimsdale JE, Ziegler MG, Hauger R, Nelesen RA, Brown M (1993): Sympathetic alterations following sodium restriction and short-term captopril. J Am Coll Cardiol 21:177-181

Mills PJ, Dimsdale JE (1993): The promise of adrenergic receptor studies in psychophysiologic research II: Applications, limitations, and progress. Psychosom Med 55:448-457

Motulsky HJ, Insel PA (1982): Adrenergic receptors in man: Direct identification, physiologic regulation, and clinical alterations. New Engl J Med 307:18-29

Nesse RM, Cameron OG, Curtis GC, McCann DS, HuberSmith MJ (1984): Adrenergic function in patients with panic anxiety. Arch Gen Psychiat 41:771-776

Pandey GN, Janicak PG, Davis JM (1987): Decreased betaadrenergic receptors in the leukocytes of depressed patients. Psychiat Res 22:265-273

Spielberger C, Gorsuch R, Lushene R, Vagg P, Facobs G (1983): Manual for the State-Trait Anxiety Inventory, STAI (Form Y). Palo Alto, CA, Consulting Psychologists Press

Stein M, O'Malley K, Klifeather S (1990): Ethnic differences in cAMP accumulation: Effect on alpha 2, beta 2, and prostanoid receptor responses. Clin Pharmacol Ther 47:360-365

Suarez EC, Shiller AD, Kuhn CM, Schanberg S, Williams RB, Zimmermann EA (1997): The relationship between hostility and beta-adrenergic receptor physiology in healthy young males. Psychosom Med 59:481-487

Wheeldon NM, Newnham DM, Coutie WJ, Peters JA, McDevitt DG, Lipworth BJ (1994): Influence of sex-steroid hormones on the regulation of lymphocyte $\beta_{2}$-adrenoceptors during the menstrual cycle. Brit J Clin Pharmaco 37:583-588 